Short Communication

\title{
Electrochemical Determination of Baicalein, Baicalin and Quercetin in Scutellaria barbata
}

\author{
Yanchun Wang ${ }^{1,2, \#}$, Zheng Wei ${ }^{3, \#}$, Junping Zhang ${ }^{3}$, and Xuemei Wang ${ }^{1,2, *}$ \\ ${ }^{1}$ People's Hospital of Zhengzhou University, Zhengzhou, 450000, Henan, P. R. China \\ ${ }^{2}$ Henan Provincial People's Hospital, Zhengzhou, 450000, Henan, P. R. China \\ ${ }^{3}$ Henan Academy institute of Traditional Chinese Medicine, Zhengzhou, 450000, Henan, P. R. China \\ *E-mail: yanchunwang96@yahoo.com \\ \# Yanchun Wang and Zheng Wei contributed equally to this work
}

doi: $10.20964 / 2016.10 .03$

Received: 29 June 2016 / Accepted: 4 August 2016 / Published: 6 September 2016

\begin{abstract}
Scutellariae barbata, a Chinese traditional medicine plant, are composed of three important components (Baicalein, baicalin and quercetin). Nowadays, to develop a simple technique for determining the containing Baicalein, baicalin and quercetin accurately and economically is highly demanded. Herein, capillary electrophoresis (CE) was incorporated with electrochemical detection (ED) to provide more sensitive and selective determination method. Baicalein, baicalin and quercetin could be well separated within 12 min using the proposed CE-ED method with the optimum conditions. The detection limits $(\mathrm{S} / \mathrm{N}=3)$ was in the concentration range of 0.214 to $0.495 \mu \mathrm{M}$ for all three analysts. Owing to the high resolution, good reproducibility and excellent stability, the CE-ED method can be successfully employed for the determination of actual samples.
\end{abstract}

Keywords: Electrochemical detection; Capillary electrophoresis; Scutellariae barbata; Baicalin; Baicalein; Quercetin

\section{$\underline{\text { FULL TEXT }}$}

(C) 2016 The Authors. Published by ESG (www.electrochemsci.org). This article is an open access article distributed under the terms and conditions of the Creative Commons Attribution license (http://creativecommons.org/licenses/by/4.0/). 